\title{
Alcohol, tobacco, and mammographic density: a population-based study
}

Anna Cabanes; ; ${ }^{1,2}$ Roberto Pastor-Barriuso;,1,2 Milagros García-López;, ${ }^{2,3}$ Carmen Pedraz-Pingarrón; ${ }^{4}$ Carmen Sánchez-Contador; Jose Antonio Vázquez Carrete; ${ }^{6}$ María Pilar Moreno; ${ }^{7}$ Carmen Vidal; ${ }^{8}$ Dolores Salas; ${ }^{9,10}$ Josefa Miranda-García;, ${ }^{9,10}$ Mercé Peris; ${ }^{8}$ Pilar Moreo; $;^{7}$ María Carmen Santamariña; ${ }^{6}$ Francisca Collado-García; ${ }^{5}$ Isabel González Román; Nieves Ascunce;,2,3 Marina Pollan;, ${ }^{1,2, *}$ and DDM-Spain. ${ }^{*}$ Corresponding author

Other members of DDMSpain:

Virginia Lope;, ${ }^{1,2}$ Beatriz Pérez-Gómez; ${ }^{1,2}$ Nuria Aragonés; ${ }^{1,2}$ Gonzalo López-Abente; ;,2 María Ederra;,3 Juana Vidán;,3 Francisco Casanova; ${ }^{2,3}$ Montserrat Corujo; ${ }^{6}$ Ana Belén Fernández; ${ }^{6}$ Soledad Abad; ${ }^{7}$ Francisco Ruiz-Perales;;,10 Maria Soledad Laso; 9,10 Manuela Alcaraz; ${ }^{9,10}$ Jesus Vioque. ${ }^{11,2}$

\section{Author's affiliations:}

1. National Center for Epidemiology. Instituto de Salud Carlos III. Madrid. Spain.

2. Consortium for Biomedical Research in Epidemiology \& Public Health (CIBER en Epidemiología y Salud Pública - CIBERESP). Spain.

3. Navarra Breast Cancer Screening Programme. Public Health Institute. Pamplona. Spain.

4. Castilla-Leon Breast Cancer Screening Programme. D.G. Salud Pública ID e I. SACYL. Castilla y León. Spain.

5. Balearic Islands Breast Cancer Screening Programme. Health Promotion for women and childhood. General Directorate Public Health and Participation. Regional Authority of Health and Consumer Affairs. Balearic Islands. Spain. 
6. Galicia Breast Cancer Screening Programme. Regional Authority of Health. Galicia Regional Government. Spain.

7. Aragon Breast Cancer Screening Programme. Health Service of Aragon. Zaragoza. Spain.

8. Cancer Prevention and Control Unit. Catalan Institute of Oncology (ICO). Barcelona. Spain.

9. Valencia Breast Cancer Screening Programme. General Directorate Public Health. Valencia. Spain.

10. Centro Superior de Investigación en Salud Pública(CSISP). Valencia. Spain.

11. Universidad Miguel Hernandez, Alicante, Spain

${ }^{*}$ Corresponding author

\section{Address for correspondence:}

Marina Pollán

Área de Epidemiología Ambiental y Cáncer

Centro Nacional de Epidemiología

Instituto de Salud Carlos III

Monforte de Lemos 5

28029 Madrid, Spain.

mpollan@isciii.es

+34918222635 


\section{ABSTRACT}

Mammographic density (MD), or the proportion of the breast with respect to its overall area that is composed of dense tissue, is a strong risk factor for breast cancer. Studies support a positive association of mammographic density and alcohol drinking.

This was a cross-sectional multicenter study based on 3584 women, aged 45 to 68 years, recruited from seven screening centers within the Spanish Breast Cancer Screening Program network. The association between MD, alcohol consumption and tobacco use was evaluated by using ordinal logistic models with random center-specific intercepts.

We found a weak positive association between current alcohol intake and higher MD, with current alcohol consumption increasing the odds of high MD by $13 \%(O R=1.13$; $95 \% \mathrm{Cl} 0.99-1.28)$ and high daily grams of alcohol being positively associated with increased MD ( $p$ for trend=0.045). There were no statistically significant differences in MD between smokers and non-smokers. Nevertheless, increased number of daily cigarettes and increased number of accumulated lifetime cigarettes were negatively associated with high MD ( $p$ for trend 0.017 and 0.021 ). The effect of alcohol on MD was modified by menopausal status and tobacco smoking: whereas alcohol consumption and daily grams of alcohol were positively associated with higher MD in postmenopausal women and in women who were not currently smoking, alcohol consumption had no effect on MD in premenopausal women and current smokers. 
Our results support an association between recent alcohol consumption and high MD, characterized by a modest increase in risk at low levels of current consumption and a decrease in risk among heavier drinkers. Our study also shows how the effects of alcohol in the breast can be modified by other factors, such as smoking.

Keywords: mammographic density, alcohol, smoking, breast cancer, ordinal logistic models

\section{LIST OF ABBREVIATIONS}

MD: Mammographic density

FFQ: Food frequency questionnaire

BMI: Body mass index

HRT: Hormone replacement therapy

E2: Estradiol

IGF-1: Insulin-like growth factor 1 


\section{INTRODUCTION}

Mammographic density (MD), or the proportion of the breast with respect to its overall breast area that is composed of dense tissue, is a strong risk factor for breast cancer. Over 40 studies have assessed this association and the majority have reported a 2- to 6-fold increased risk of breast cancer for the highest to lowest density categories (1).

Breast density is also associated with reproductive and anthropometric risk factors for breast cancer (2-13). However, the association between MD and breast cancer appears to be independent, and usually persists after adjustment for these factors. In addition, there is strong evidence of a genetic determinant of MD (14).

Although relatively few studies have examined the association between alcohol consumption and breast density, most nonetheless report higher MD among alcohol drinkers than abstainers (15-19). Whereas some of these studies support a weak, albeit significant, positive association between current alcohol intake and MD in both pre- and postmenopausal women, there is more limited and inconclusive data on the association between the timing of initiation of alcohol intake and MD $(19,20)$.

Even less information is available on the effects of tobacco smoking on breast density. Some studies consistently report an inverse relationship between current smoking and MD $(7,15,21,22)$, attributed to an antiestrogenic effect of tobacco smoke; others, in contrast, fail to observe any association $(23,24)$.

Accordingly, we decided to investigate the association between alcohol consumption, smoking and adult MD using data from food frequency questionnaires (FFQs), risk factor data, and breast density measures from the Determinants of Mammographic Density in Spain study (DDM-Spain). 


\section{MATERIALS AND METHODS}

\section{Study population}

This was a cross-sectional multicenter study based on 3584 women, aged 45 to 68 years, recruited from seven specific screening centers within the Spanish Breast Cancer Screening Program network. All women aged 50-65 years, regardless of nationality or legal status, are screened under these government-sponsored programs every two years, with the exception of women carrying BRCA1 or BRCA2 mutations who are generally screened by specific units. In some regions, women between 45-49 years of age are also included. Furthermore, the age range in all regional programs is currently being extended to cover women up to the age of 70 years.

\section{Sampling procedure and data-collection}

A minimum of 500 women per screening center were recruited from October 7, 2007 to July 14 , 2008. Women previously diagnosed with breast cancer or some other malignant disease (except basal cell epitheliomas) were excluded, as were women who failed to respond to the questionnaire or presented with some physical inability that prevented a mammography from being performed. The DDM-Spain study protocol was formally approved by the Institutional Review Board at the Carlos III Institute of Health.

Women were interviewed at the screening center by purpose-trained interviewers. The questionnaire collected demographic information relating to the following: childhood and youth; family and personal background; gynecologic, obstetric and occupational history; household activities; current and lifetime alcohol consumption; current and lifetime tobacco use; current and past physical activity; and diet during the preceding year. Women's height and weight were measured twice by the interviewer, with a third 
measurement being taken if the first two were in any way dissimilar. Average values were used to compute BMI.

The dietary section of the questionnaire ascertained the frequency of consumption and usual portion size of 117 food items (including alcoholic beverages), and was used to estimate daily intake of alcohol and calories. The standard servings of red wine [125ml], white wine [125ml], beer [200ml], sherry [50ml], hard cider [125ml], spirits [30ml], and brandy, gin, rum, whisky and vodka [40ml], were estimated to contain $13.25 \mathrm{~g}, 12.63 \mathrm{~g}, 6.15 \mathrm{~g}, 3.06 \mathrm{~g}, 7.80 \mathrm{~g}, 7.40 \mathrm{~g}$, and $14.25 \mathrm{~g}$ of ethanol, respectively. Daily calorie intake was estimated from a nutrient database developed by Vioque et al (25). The folate intake values comprised dietary sources and vitamin supplements.

\section{Estimation of percent breast density}

We measured MD from the craniocaudal mammogram of the left breast using Boyd's semiquantitative scale, a visual scale that rates density in 6 categories, namely: A (0\%); B (<10\%); C (10-25\%); D (25-50\%); E (50-75\%); and F (>75\%). Mammographic density was assessed on a blind, anonymous basis by a single, experienced radiologist.

\section{Statistical analysis}

The association between MD, alcohol consumption and tobacco use was evaluated by using ordinal logistic models with random center-specific intercepts (26). The main exposure variables, as well as the remaining adjustment factors, were regarded as fixed effects, so that their associated ORs were deemed to be the same for women at all screening centers. In addition, the ordinal logistic models included a random, centerspecific intercept term that accounted for unexplained variations in the baseline odds of higher MDs across screening centers. 
The Brant test was used to verify the proportional odds assumption. This assumption held for the effects of alcohol consumption and tobacco use in all fitted models, after the two lowest categories ( $\mathrm{A}$ and $\mathrm{B}$ ) of Boyd's classification had been combined. These categories are fairly similar in terms of reduced percentage of dense breast tissue $(0$ and $<10 \%$, and there were only $4.2 \%$ of women in the "no dense tissue" category. Hence, all logistic models included MD as an ordinal response variable with five categories $(A+B, C, D, E$, and $F)$.

The main exposures of interest linked to alcohol consumption were: (a) current alcohol intake (yes or no); (b) lifetime alcohol drinking (never, past, or current drinker); (c) average alcohol intake during preceding year as reported in the FFQ (grams/day); and (d) age at which regular drinking had been initiated. Insofar as tobacco use was concerned, the exposures of interest were: (e) current smoking (yes or no); (f) lifetime tobacco smoking (never, past, or current smoker); (g) daily amount of cigarettes; (h) accumulated amount of cigarettes; and (i) age at which smoking had been initiated. All these exposures were analyzed as categorical variables, except for daily grams of alcohol, daily and accumulated amount of cigarettes, and age of initiation of alcohol and tobacco use, which were modeled both as predetermined categorical and continuous variables.

To further explore the association between amount of alcohol intake and MD without assuming a linear dose-response relationship, we used restricted quadratic splines for log-transformed alcohol intakes, with knots at 0.09, 3.3, and $33.1 \mathrm{~g} /$ day, corresponding to the $5^{\text {th }}, 50^{\text {th }}$ and $95^{\text {th }}$ percentiles of alcohol consumption among drinkers, respectively. These spline models require the same number of parameters as the categorical analysis but can accommodate a wide variety of smoothed risk trends (27). 
In addition, the above models were fitted with increasing levels of adjustment. First, we fitted a simple model adjusted for strong determinants of $M D$, i.e., age at mammography (continuous), BMI (restricted quadratic spline), and menopausal status. Second, we fitted an extended model, further adjusted for variables associated both with lifestyle and MD, including number of live births (continuous), current HRT use, current alcohol intake, and current smoking. Separate simple and extended models were constructed for pre- and postmenopausal women. Furthermore, the effect of alcohol consumption was separately assessed in current and noncurrent smokers.

All analyses were performed in Stata (StataCorp LP, College Station, TX), using the gllamm function to fit random-intercept ordinal logistic models (28), and R statistical software (R Foundation for Statistical Computing, Vienna, Austria).

\section{RESULTS}

Of the three thousand, five hundred, eighty-four (3584) women recruited and interviewed, MD assessment was completed for 3568. The average participation rate was $74.5 \%(64.7-84.0 \%)$. Women who developed breast cancer within 6 months of mammography were excluded from the analysis $(n=10)$. Daily calorie intake below 800 calories or above 4000 was considered unrealistic, and the women concerned were also excluded $(n=8)$ along with one woman who was being fed intravenously.

The overall proportion of Boyd mammographic density categories in the study population was as follows: $A, n=150$ (4.2\%); $B, n=722$ (20.3\%); C, $n=732$ (20.7\%); D, $n=1135$ (32\%); $E, n=623$ (17.5\%); and $F, n=187$ (5.3\%). Twenty-one percent of women were pre- or perimenopausal, and $79 \%$ were postmenopausal. With respect to alcohol consumption, $41.6 \%$ were abstainers, $41.1 \%$ currently drank up to $10 \mathrm{~g}$ of alcohol/day, and only $17.3 \%$ consumed more than $10 \mathrm{~g}$ of alcohol/day. In the case of tobacco use, 
$57.8 \%$ of participants had never smoked, $24.3 \%$ currently smoked, and $17.9 \%$ were exsmokers.

In a simple analysis adjusted for age, BMI, menopausal status and screening program, higher MD was positively associated with never being pregnant, older age at first live birth, larger daily caloric intake and more years of education (Table 1). In contrast, higher MD was negatively associated with increased age; younger age at menopause, increased number of live births; being postmenopausal; having osteoporosis; and being very active between the ages of 36 and 50 years. Age at menarche, HRT use, folic acid intake and tobacco smoking were considered potential confounders, but in our study were not associated with MD.

After an extended analysis adjusted for age, screening program, BMI, menopausal status, number of live births, HRT use, current alcohol consumption and current tobacco use, osteoporosis and high levels of physical activity remained associated with decreased odds of being in high MD groups (OR=0.71;95\% Cl 0.59-0.86 and $\mathrm{OR}=0.86 ; 95 \% \mathrm{Cl} 0.75-0.98$, respectively), and daily calorie intake was associated with increased odds of being in high-density categories (highest versus lowest calorie intake OR=1.33; 95\% Cl 1.11-1.59; $p$ for trend=0.003)(Table 1).

Alcohol was positively related with MD (Table 1). In the extended model, current alcohol drinking increased the odds of high MD by $13 \%(\mathrm{OR}=1.13 ; 95 \% \mathrm{Cl} 0.99-1.28)$, with high daily grams of alcohol being positively associated with increased MD ( $p$ for trend=0.045; Table 1). Among drinkers, older age of initiation of alcohol consumption was only slightly associated with a higher probability of being in high MD categories, though the statistical test was not significant at $p<0.05$ (Table 1). In contrast, women who started drinking before menarche had a lower probability of being in higher density categories than did other women who also consumed alcohol. Further adjustment for 
daily calorie intake, physical activity levels, and osteoporosis failed to change the magnitude of the associations (data not shown) and so these variables were not included in the final analysis.

There were no statistically significant differences in MD between smokers and nonsmokers. Nevertheless, increased number of daily cigarettes and increased number of accumulated lifetime cigarettes were negatively associated with high MD in the extended adjusted model ( $p$ for trend 0.008 and 0.004 , respectively). Age of smoking initiation had no influence on MD (Table 1).

Although formal testing showed no statistical interactions between menopausal status and variables linked to alcohol consumption and tobacco use (likelihood ratio test; $p>0.05)$, in view of the strong influence of ovarian hormones on MD and the reported estrogenic or antiestrogenic effects of alcohol and tobacco on the breast, extended models were constructed separately for pre- and postmenopausal women (Table 2).

In peri- and premenopausal women, alcohol consumption was not associated with MD and the dose-response curve was almost flat (Fig. 1). Increased age of initiation of alcohol consumption seemed to be associated with higher MD, though the number of women in the older age groups was small.

Among postmenopausal women, in contrast, alcohol consumption increased the odds of being in high MD categories by $15 \%$ relative to abstainers $(\mathrm{OR}=1.15 ; 95 \% \mathrm{Cl} 1.00$ 1.32). Raising daily alcohol consumption resulted in a dose-dependent increase in the likelihood of being in a high MD group ( $p$ for trend=0.022). In comparison with abstaining, drinking more than $10 \mathrm{~g}$ of alcohol/day increased the probability of having MD by $26 \%(\mathrm{OR}=1.26 ; 95 \% \mathrm{Cl} 1.03-1.53)$. Using restricted quadratic splines, we observed increased odds of being in high MD groups with increasing amounts of 
alcohol but the relationship was not linear. Whereas moderate daily intake of alcohol (less than one glass of red wine) increased mammographic density, higher alcohol intake led to a lower probability of having high MD (Fig. 1).

Postmenopausal women displayed a negative association between the number of cigarettes -both current and accumulated over a lifetime- and the odds of being in high MD groups. Women who smoked more than 15 cigarettes/day were $32 \%$ less likely to be in high MD categories than were women who smoked $0-5$ cigarettes/day $(O R=0.68$; 95\% Cl 0.46-0.99; $p$ for trend=0.046); and similarly, women who had smoked more than 700 cigarettes in their lifetime were $30 \%$ less likely to be in high MD categories than were women who had smoked fewer than 300 cigarettes $(\mathrm{OR}=0.70 ; 95 \% \mathrm{Cl} 0.51$ 0.96 ; $p$ for trend $=0.053$ ).

We found that an interaction test between alcohol and tobacco use with respect to their influence on mammographic density approached statistical significance (likelihood ratio test $p=0.075$ ). The effects of increasing tobacco consumption on MD were different depending on the level of alcohol intake. In the highest alcohol consumption group (women who drank more than $10 \mathrm{~g}$ of alcohol/day), the odds of being in high MD categories decreased by $17 \%$ for every increase of 10 cigarettes/day $(p=0.037)$ compared to women that do not drink. In women who drank less than $10 \mathrm{~g} /$ day, however, the increased number of daily cigarettes showed no association with lower MD $(p=0.976)$. Moreover, alcohol consumption and smoking are interrelated, in that heavy drinkers tend to smoke more than do light drinkers or abstainers. In the DDMSpain study, while only $4 \%$ of abstainers smoked over 20 cigarettes a day, $9 \%$ of women in the highest alcohol intake levels (>20 g/day) smoked over 20 cigarettes a day. 
Given the strong antiestrogenic effects reported for tobacco smoking, extended models for alcohol consumption were separately fitted for current and noncurrent smokers (Table 3). There was a positive association between increased daily grams of alcohol and high MD among noncurrent smokers (women who drank more than $10 \mathrm{~g}$ of alcohol/day versus abstainers $\mathrm{OR}=1.25 ; 95 \% \mathrm{Cl} 1.02-1.53 ; p$ for trend 0.029$)$. Increasing the amount of alcohol consumed raised the odds of being in a higher density group ( $p$ for trend=0.029). Whereas older age of alcohol initiation increased the probability of being in higher MD groups, starting to drink alcohol before menarche decreased the odds of being in high MD categories by $50 \%(\mathrm{OR}=0.50 ; 95 \% \mathrm{Cl} 0.29$ 0.85). Among current smokers, in contrast, no association was observed between drinking alcohol, increased alcohol consumption or age of initiation into alcohol drinking and MD. The effects of alcohol on MD were observed solely for women who were not current smokers.

\section{DISCUSSION}

This paper reports a positive association between current alcohol intake and higher MD. The effect of alcohol on MD was mainly observed among postmenopausal women. Furthermore, whereas alcohol consumption and daily grams of alcohol were positively associated with higher MD among women who were not current smokers, alcohol consumption failed to show any effect on MD among current smokers.

In general, the positive association observed for current drinking is in line with much of the literature on alcohol and MD $(15,17-20,29,30)$. Even though the interaction test between menopausal status and alcohol consumption was not statistically significant in our study, a different effect in pre- versus postmenopausal women has been described elsewhere $(15,17)$. To our knowledge, no other study has yet reported an opposite effect of smoking and alcohol drinking on MD. 
We failed to find a consistent association between age at which women started consuming alcohol and MD. However, our results suggest that the timing of exposure to alcohol affected MD in several different ways. First, later age of initiation of alcohol consumption was positively related (although not statistically significant) with a higher probability of being in high-density categories in premenopausal women versus women who started drinking at early ages. Conversely, women who started drinking alcohol before menarche were half as likely to be in high MD groups as women who started drinking after menarche. This is in agreement with reports showing that prepubertal estrogenic exposures reduce MD $(31,32)$ while estrogenic exposures during adulthood increase it $(2,33-35)$.

Thus, alcohol may have different effects on MD, depending on the time of exposure, i.e., whereas starting to drink during peripubertal years reduces the odds of being in high mammographic density groups, starting to drink during adulthood has no effect on MD unless it occurs close to the date of mammography. This agrees both with reports suggesting that drinking alcohol before age 21 years is inversely associated with mammary density (20), and with others showing that current rather than lifetime alcohol intake is more strongly associated with MD (19). In this regard, we created a variable representing the time elapsed between initiation of alcohol consumption and mammography, and found that the likelihood of being in a higher Boyd category of MD increased as initiation approached mammography, which suggests that starting to drink increases MD but that the initial effect of alcohol wanes over time. This is not the only estrogenic exposure with this paradoxical effect: one study has found that the effects of estrogen-plus-progestin therapy on MD persist but are attenuated after 2 years of treatment (33). 
Our finding of a weak, negative association between current smoking and MD supports most $(7,21,22)$ but not all $(23,24,36)$ prior published reports, and is consistent with an antiestrogenic effect of cigarette smoking on breast tissue. While MD and daily number of cigarettes smoked were found to have an inverse relationship, neither age at initiation nor smoking duration displayed an association.

According to our results, the effects of both exposures -alcohol and tobacco- on MD may work in opposite directions, which could explain why the OR of the effect of alcohol consumption on MD among smokers was close to one and why there was a decrease in risk of high MD with increased number of daily cigarettes among heavy drinkers. An antagonistic effect would also explain the unexpected decline at the end of the dose-response curve of alcohol intake and MD in postmenopausal women. Alcohol consumption and smoking are interrelated, in that heavy drinkers tend to smoke more than do light drinkers or abstainers. However, women in the highest alcohol consumption group may have been different in other lifestyle aspects, and so residual confounding by unknown factors at high alcohol intake levels cannot be ruled out.

One potential limitation of this study is the error inherent in dietary assessment in such a large epidemiologic study. However, the semiquantitative FFQ was adapted from Willett et al. (37) for the Spanish population, and has demonstrated reasonable levels of reliability and validity in other studies (25). Further, we found that the association of MD with general reproductive variables such as age at first birth, number of live births, age at menarche and menopause $(2,3)$, etc, as well as osteoporosis (38), level of physical activity $(39,40)$ or daily caloric intake $(41)$ were consistent with what is known about MD. These observed findings provide additional support for the validity of the questionnaire that was used in this study. 
Low alcohol consumption and low prevalence of regular adolescent drinking among the study population constitute two further possible drawbacks of our study: only $17 \%$ of the women drank more than $10 \mathrm{~g}$ of alcohol/day, and less than $19 \%$ of the women started drinking at age 18 years or before. Another potential limitation resides in the length of time between adolescence and recall of alcohol consumption later in life. Even though other studies have shown good reliability of reporting past alcohol consumption (42), recall of exposures during adolescence is likely to be imprecise and could result in attenuation of estimates.

Similarly, the measure of breast density was subjectively determined by only one radiologist. Nevertheless, the intra-observer reproducibility of the Boyd scale was good in our study, with a concordance between the first and second reading of 0.92 (43). Indeed, all disagreements corresponded to differences in only one category.

In summary, our results provide further support for an association between recent alcohol consumption and high mammographic density, characterized by a modest increase in risk at low levels of current consumption and a decrease in risk among heavier drinkers. Our study also suggests that the effects of alcohol in the breast can be modified by other factors, such as smoking. Yet, to what precise degree tobacco use may explain the lack of increased MD among women who drink alcoholic beverages daily is difficult to establish. Alcohol drinking is a modifiable behavior, and since moderate alcohol consumption is associated with a reduced risk of cardiovascular mortality and overall mortality among women, studies such as ours, which address the link between alcohol consumption and breast cancer risk, are critical for ascertaining the cost-benefit ratio of alcohol intake. 


\section{ACKNOWLEDGMENTS}

We should like to thank the participants in the DDM-Spain study for their contribution to breast cancer research.

This study was supported by: Research Grant FIS PI060386 from Spain's Health Research Fund (Fondo de Investigación Sanitaria); the EPY 1306/06 Collaboration Agreement between Astra-Zeneca and the Carlos III Institute of Health (Instituto de Salud Carlos III); and a grant from the Spanish Federation of Breast Cancer. 


\section{REFERENCES}

(1) McCormack VA, Dos SS, I. Breast density and parenchymal patterns as markers of breast cancer risk: a meta-analysis. Cancer Epidemiol Biomarkers Prev 2006; 15(6):1159-1169.

(2) Titus-Ernstoff L, Tosteson AN, Kasales C, Weiss J, Goodrich M, Hatch EE et al. Breast cancer risk factors in relation to breast density (United States). Cancer Causes Control 2006; 17(10):1281-1290.

(3) Butler LM, Gold EB, Greendale GA, Crandall CJ, Modugno F, Oestreicher N et al. Menstrual and reproductive factors in relation to mammographic density: the Study of Women's Health Across the Nation (SWAN). Breast Cancer Res Treat 2007.

(4) Johansson H, Gandini S, Bonanni B, Mariette F, Guerrieri-Gonzaga A, Serrano D et al. Relationships between circulating hormone levels, mammographic percent density and breast cancer risk factors in postmenopausal women. Breast Cancer Res Treat 2008; 108(1):57-67.

(5) Yong M, Atkinson C, Newton KM, Aiello Bowles EJ, Stanczyk FZ, Westerlind $\mathrm{KC}$ et al. Associations between endogenous sex hormone levels and mammographic and bone densities in premenopausal women. Cancer Causes Control 2009; 20(7):1039-1053.

(6) Walker K, Fletcher O, Johnson N, Coupland B, McCormack VA, Folkerd E et al. Premenopausal mammographic density in relation to cyclic variations in endogenous sex hormone levels, prolactin, and insulin-like growth factors. Cancer Res 2009; 69(16):6490-6499. 
(7) Bremnes $Y$, Ursin G, Bjurstam N, Gram IT. Different measures of smoking exposure and mammographic density in postmenopausal Norwegian women: a cross-sectional study. Breast Cancer Res 2007; 9(5):R73.

(8) Noh JJ, Maskarinec G, Pagano I, Cheung LW, Stanczyk FZ. Mammographic densities and circulating hormones: a cross-sectional study in premenopausal women. Breast 2006; 15(1):20-28.

(9) Verheus M, Peeters PH, van Noord PA, van der Schouw YT, Grobbee DE, van Gils $\mathrm{CH}$. No relationship between circulating levels of sex steroids and mammographic breast density: the Prospect-EPIC cohort. Breast Cancer Res 2007; 9(4):R53.

(10) Tamimi RM, Hankinson SE, Colditz GA, Byrne C. Endogenous sex hormone levels and mammographic density among postmenopausal women. Cancer Epidemiol Biomarkers Prev 2005; 14(11 Pt 1):2641-2647.

(11) Diorio C, Pollak M, Byrne C, Masse B, Hebert-Croteau N, Yaffe M et al. Insulinlike growth factor-I, IGF-binding protein-3, and mammographic breast density. Cancer Epidemiol Biomarkers Prev 2005; 14(5):1065-1073.

(12) Byrne C, Colditz GA, Willett WC, Speizer FE, Pollak M, Hankinson SE. Plasma insulin-like growth factor (IGF) I, IGF-binding protein 3, and mammographic density. Cancer Res 2000; 60(14):3744-3748.

(13) Boyd NF, Stone J, Martin LJ, Jong R, Fishell E, Yaffe M et al. The association of breast mitogens with mammographic densities. Br J Cancer 2002; 87(8):876882. 
(14) Vachon CM, Sellers TA, Carlson EE, Cunningham JM, Hilker CA, Smalley RL et al. Strong evidence of a genetic determinant for mammographic density, a major risk factor for breast cancer. Cancer Res 2007; 67(17):8412-8418.

(15) Vachon CM, Kushi LH, Cerhan JR, Kuni CC, Sellers TA. Association of diet and mammographic breast density in the Minnesota breast cancer family cohort. Cancer Epidemiol Biomarkers Prev 2000; 9(2):151-160.

(16) Brisson J, Verreault R, Morrison AS, Tennina S, Meyer F. Diet, mammographic features of breast tissue, and breast cancer risk. Am J Epidemiol 1989; $130(1): 14-24$

(17) Maskarinec G, Takata Y, Pagano I, Lurie G, Wilkens LR, Kolonel LN. Alcohol consumption and mammographic density in a multiethnic population. Int $\mathrm{J}$ Cancer 2006; 118(10):2579-2583.

(18) Masala G, Ambrogetti D, Assedi M, Giorgi D, Del Turco MR, Palli D. Dietary and lifestyle determinants of mammographic breast density. A longitudinal study in a Mediterranean population. Int J Cancer 2006; 118(7):1782-1789.

(19) Flom JD, Ferris JS, Tehranifar P, Terry MB. Alcohol intake over the life course and mammographic density. Breast Cancer Res Treat 2009; 117(3):643-651.

(20) Vachon CM, Sellers TA, Janney CA, Brandt KR, Carlson EE, Pankratz VS et al. Alcohol intake in adolescence and mammographic density. Int J Cancer 2005; 117(5):837-841.

(21) Jeffreys M, Warren R, Gunnell D, McCarron P, Smith GD. Life course breast cancer risk factors and adult breast density (United Kingdom). Cancer Causes Control 2004; 15(9):947-955. 
(22) Butler LM, Gold EB, Conroy SM, Crandall CJ, Greendale GA, Oestreicher N et al. Active, but not passive cigarette smoking was inversely associated with mammographic density. Cancer Causes Control 2010; 21(2):301-311.

(23) Gapstur SM, Lopez P, Colangelo LA, Wolfman J, Van Horn L, Hendrick RE. Associations of breast cancer risk factors with breast density in Hispanic women. Cancer Epidemiol Biomarkers Prev 2003; 12(10):1074-1080.

(24) Roubidoux MA, Kaur JS, Griffith KA, Stillwater B, Novotny P, Sloan J. Relationship of mammographic parenchymal patterns to breast cancer risk factors and smoking in Alaska Native women. Cancer Epidemiol Biomarkers Prev 2003; 12(10):1081-1086.

(25) Vioque J. Validez de la evaluación de la ingesta dietética. In: Serra-Majem L, Aranceta J, editors. Nutrición y Salud Pública. Métodos, bases científicas y aplicaciones. Barcelona: Mason-Elsevier, 2006: 199-210.

(26) Gelman A, Hill J. Data Analysis using Regression and Multilevel/ Hierarchical Models. Cambridge: Cambridge University Press., 2007.

(27) Greenland S. Dose-response and trend analysis in epidemiology: alternatives to categorical analysis. Epidemiology 1995; 6(4):356-365.

(28) Rabe-Hesketh S, Skrondal A, Pickles A. Generalized Linear Latent and Mixed Models. http://www.gllamm.org/ . 2010.

(29) Boyd NF, Connelly P, Byng J, Yaffe M, Draper H, Little L et al. Plasma lipids, lipoproteins, and mammographic densities. Cancer Epidemiol Biomarkers Prev $1995 ; 4(7): 727-733$. 
(30) Herrinton LJ, Saftlas AF, Stanford JL, Brinton LA, Wolfe JN. Do alcohol intake and mammographic densities interact in regard to the risk of breast cancer? Cancer 1993; 71(10):3029-3035.

(31) Cabanes A, Wang M, Olivo S, DeAssis S, Gustafsson JA, Khan G et al. Prepubertal estradiol and genistein exposures up-regulate BRCA1 mRNA and reduce mammary tumorigenesis. Carcinogenesis 2004; 25(5):741-748.

(32) Jordan HL, Hopper JL, Thomson RJ, Kavanagh AM, Gertig DM, Stone J et al. Influence of high-dose estrogen exposure during adolescence on mammographic density for age in adulthood. Cancer Epidemiol Biomarkers Prev 2010; 19(1):121-129.

(33) McTiernan A, Martin CF, Peck JD, Aragaki AK, Chlebowski RT, Pisano ED et al. Estrogen-plus-progestin use and mammographic density in postmenopausal women: Women's Health Initiative randomized trial. J Natl Cancer Inst 2005; 97(18):1366-1376.

(34) McTiernan A, Wang CY, Sorensen B, Xiao L, Buist DS, Aiello Bowles EJ et al. No effect of aspirin on mammographic density in a randomized controlled clinical trial. Cancer Epidemiol Biomarkers Prev 2009; 18(5):1524-1530.

(35) Marchesoni D, Driul L, lanni A, Fabiani G, Della MM, Zuiani C et al. Postmenopausal hormone therapy and mammographic breast density. Maturitas 2006; 53(1):59-64.

(36) Vachon CM, Kuni CC, Anderson K, Anderson VE, Sellers TA. Association of mammographically defined percent breast density with epidemiologic risk factors for breast cancer (United States). Cancer Causes Control 2000; 11(7):653-662. 
(37) Willett WC, Sampson L, Stampfer MJ, Rosner B, Bain C, Witschi J et al. Reproducibility and validity of a semiquantitative food frequency questionnaire. Am J Epidemiol 1985; 122(1):51-65.

(38) Crandall CJ, Zheng Y, Karlamangla A, Sternfeld B, Habel LA, Oestreicher N et al. The association between mammographic breast density and bone mineral density in the study of women's health across the nation. Ann Epidemiol 2007; 17(8):575-583.

(39) Masala G, Assedi M, Ambrogetti D, Sera F, Salvini S, Bendinelli B et al. Physical activity and mammographic breast density in a Mediterranean population: the EPIC Florence longitudinal study. Int J Cancer 2009; 124(7):1654-1661.

(40) Oestreicher N, Capra A, Bromberger J, Butler LM, Crandall CJ, Gold EB et al. Physical activity and mammographic density in a cohort of midlife women. Med Sci Sports Exerc 2008; 40(3):451-456.

(41) Mishra GD, Hardy R, Cardozo L, Kuh D. Body weight through adult life and risk of urinary incontinence in middle-aged women: results from a British prospective cohort. Int J Obes (Lond) 2008; 32(9):1415-1422.

(42) Longnecker MP, Newcomb PA, Mittendorf R, Greenberg ER, Clapp RW, Bogdan $\mathrm{G}$ et al. The reliability of self-reported alcohol consumption in the remote past. Epidemiology 1992; 3(6):535-539.

(43) Garrido EM, Ruiz-Perales F, Miranda J, Ascunce N, Gonzalez-Roman I, Sanchez-Contador $\mathrm{C}$ et al. Evaluation of mammographic density patterns: reproducibility and concordance among scales. BMC Cancer 2010; 10(1):485. 


\section{FIGURE LEGENDS}

\section{Figure 1}

Odds ratio of higher mammographic density (MD) according to alcohol intake in premenopausal (top) and postmenopausal women (bottom). Curves depict adjusted odds ratios (solid lines) and their 95\% confidence intervals (dashed lines), based on restricted quadratic splines for log-transformed alcohol intakes with knots at $5^{\text {th }}, 50^{\text {th }}$, and $95^{\text {th }}$ percentiles among drinkers. The reference value $(O R=1)$ was set at 0.01 g/day (abstainers). Odds ratios were obtained from an ordinal logistic model with random program-specific intercepts, adjusted for age, BMI, current smoking status, number of live births, and current use of HRT (only for postmenopausal women). Bars represent the frequency distribution of alcohol intake among pre- and postmenopausal women.

TABLE 1. Characteristics of study population according to Boyd' mammographic density categoriese, associated ORs and $95 \%$ Cls for a higher Bo category.

\begin{tabular}{|c|c|c|c|c|c|c|c|c|c|c|c|c|c|}
\hline \multirow[b]{2}{*}{ VARIABLES } & \multirow[b]{2}{*}{$\mathrm{N}$} & \multicolumn{5}{|c|}{ Boyd Scale (\%) } & \multicolumn{4}{|c|}{ Simple Model ${ }^{1}$} & \multicolumn{3}{|c|}{ Extended Model ${ }^{2}$} \\
\hline & & $\begin{array}{c}A+B \\
<10 \%\end{array}$ & $\begin{array}{c}C \\
10- \\
25 \% \\
\end{array}$ & $\begin{array}{c}\mathrm{D} \\
25- \\
50 \% \\
\end{array}$ & $\begin{array}{c}E \\
50- \\
75 \% \\
\end{array}$ & $\begin{array}{c}F \\
>75 \%\end{array}$ & OR & $95 \% \mathrm{Cl}$ & $p$ & $\begin{array}{l}p \text { for } \\
\text { trend }^{*}\end{array}$ & OR & $95 \% \mathrm{Cl}$ & $p$ \\
\hline \multicolumn{14}{|l|}{ Age $(y)$} \\
\hline$<50 y$ & 547 & 10 & 13 & 35 & 31 & 11 & 1.00 & & & & 1.00 & & \\
\hline $50-54 y$ & 968 & 20 & 19 & 33 & 22 & 7 & 0.81 & $0.65-1.02$ & 0.071 & & 0.83 & $0.66-1.04$ & 0.119 \\
\hline $55-59$ y & 1000 & 25 & 25 & 33 & 14 & 4 & 0.68 & $0.53-0.87$ & 0.002 & & 0.72 & $0.55-0.93$ & 0.011 \\
\hline $60-64$ y & 939 & 37 & 22 & 29 & 10 & 2 & 0.45 & $0.35-0.58$ & $<0.001$ & & 0.49 & $0.37-0.64$ & $<0.001$ \\
\hline$>65 y$ & 95 & 38 & 23 & 24 & 12 & 3 & 0.41 & $0.26-0.63$ & $<0.001$ & $<0.001$ & 0.44 & $0.28-0.68$ & $<0.001$ \\
\hline \multicolumn{14}{|l|}{ BMI (kg/m2) } \\
\hline$<25$ & 977 & 10 & 14 & 35 & 29 & 11 & 1.00 & & & & 1.00 & & \\
\hline $25-30$ & 1516 & 22 & 23 & 33 & 18 & 4 & 0.48 & $0.41-0.56$ & $<0.001$ & & 0.49 & $0.42-0.57$ & $<0.001$ \\
\hline$>30$ & 1056 & 42 & 23 & 27 & 6 & 2 & 0.18 & $0.16-0.22$ & $<0.001$ & $<0.001$ & 0.20 & $0.17-0.24$ & $<0.001$ \\
\hline \multicolumn{14}{|c|}{ Number of live births } \\
\hline 1 & 543 & 17 & 17 & 33 & 27 & 6 & 1.00 & & & & 1.00 & & \\
\hline 2 & 1701 & 24 & 21 & 33 & 17 & 5 & 0.72 & $0.61-0.86$ & $<0.001$ & & 0.77 & $0.64-0.92$ & 0.004 \\
\hline 3 & 715 & 29 & 24 & 29 & 14 & 4 & 0.65 & $0.53-0.80$ & $<0.001$ & & 0.73 & $0.59-0.90$ & 0.003 \\
\hline$\geq 4$ & 272 & 42 & 26 & 26 & 3 & 2 & 0.40 & $0.31-0.53$ & $<0.001$ & & 0.48 & $0.36-0.63$ & $<0.001$ \\
\hline Nulliparous & 318 & 15 & 15 & 35 & 23 & 12 & 1.33 & $1.03-1.72$ & 0.029 & $<0.001$ & 1.40 & $1.08-1.81$ & 0.010 \\
\hline \multicolumn{14}{|c|}{ Age at 1st birth (y) } \\
\hline$<20$ & 155 & 26 & 30 & 23 & 16 & 5 & 1.00 & & & & 1.00 & & \\
\hline $20-24$ & 1340 & 29 & 23 & 30 & 15 & 4 & 0.96 & $0.71-1.29$ & 0.771 & & 0.88 & $0.65-1.20$ & 0.422 \\
\hline
\end{tabular}




\begin{tabular}{|c|c|c|c|c|c|c|c|c|c|c|c|c|c|}
\hline 25-29 \& nulliparous & 1546 & 23 & 19 & 35 & 17 & 6 & 1.20 & $0.89-1.62$ & 0.231 & & 0.94 & $0.69-1.28$ & 0.717 \\
\hline$\geq 30$ & 465 & 18 & 17 & 31 & 27 & 6 & 1.38 & $0.99-1.92$ & 0.060 & 0.053 & 1.04 & $0.74-1.46$ & 0.832 \\
\hline \multicolumn{14}{|l|}{ Education } \\
\hline $5^{\text {th }}$ grade & 1203 & 31 & 23 & 31 & 11 & 3 & 1.00 & & & & 1.00 & & \\
\hline Below $8^{\text {th }}$ grade & 1314 & 25 & 21 & 31 & 18 & 5 & 1.07 & $0.92-1.24$ & 0.379 & & 1.03 & $0.89-1.20$ & 0.685 \\
\hline Below $12^{\text {th }}$ grade & 664 & 18 & 19 & 31 & 25 & 6 & 1.21 & $1.01-1.46$ & 0.042 & & 1.13 & $0.94-1.36$ & 0.202 \\
\hline University degree & 362 & 17 & 15 & 38 & 22 & 9 & 1.25 & $1.00-1.56$ & 0.052 & 0.016 & 1.09 & $0.87-1.37$ & 0.475 \\
\hline \multicolumn{14}{|l|}{ Age at menarche } \\
\hline$\geq 14 \mathrm{y}$ & 1174 & 23 & 21 & 31 & 19 & 5 & 1.00 & & & & 1.00 & & \\
\hline $12-13 y$ & 1564 & 23 & 20 & 33 & 18 & 5 & 1.07 & $0.93-1.23$ & 0.350 & & 1.05 & $0.91-1.21$ & 0.498 \\
\hline$<12 y$ & 802 & 29 & 22 & 30 & 14 & 5 & 0.94 & $0.80-1.12$ & 0.505 & 0.644 & 0.92 & $0.78-1.09$ & 0.336 \\
\hline \multicolumn{14}{|l|}{ Age at menopause } \\
\hline $50-54$ y & 1170 & 27 & 21 & 34 & 14 & 4 & 1.00 & & & & 1.00 & & \\
\hline$\geq 55 \mathrm{y}$ & 250 & 39 & 24 & 26 & 10 & 1 & 0.83 & $0.64-1.07$ & 0.151 & & 0.82 & $0.63-1.06$ & 0.136 \\
\hline$\leq 45 y$ & 496 & 28 & 26 & 29 & 12 & 5 & 0.81 & $0.67-0.99$ & 0.039 & & 0.83 & $0.68-1.01$ & 0.060 \\
\hline $45-49$ & 854 & 26 & 23 & 32 & 15 & 4 & 0.88 & $0.75-1.04$ & 0.140 & & 0.89 & $0.75-1.05$ & 0.159 \\
\hline Premenopausal & 758 & 12 & 13 & 34 & 32 & 10 & 1.44 & $1.17-1.78$ & 0.001 & 0.152 & 1.42 & $1.15-1.76$ & 0.001 \\
\hline \multicolumn{14}{|l|}{ HRT } \\
\hline Never & 3043 & 24 & 21 & 32 & 18 & 5 & 1.00 & & & & 1.00 & & \\
\hline Current hormones & 154 & 22 & 19 & 32 & 18 & 8 & 1.13 & $0.84-1.53$ & 0.420 & & 0.98 & $0.72-1.32$ & 0.882 \\
\hline Past hormones & 301 & 30 & 21 & 32 & 14 & 4 & 0.86 & $0.69-1.07$ & 0.173 & & 0.85 & $0.68-1.06$ & 0.160 \\
\hline Raloxifen & 51 & 27 & 27 & 35 & 6 & 4 & 0.70 & $0.42-1.15$ & 0.160 & & 0.71 & $0.43-1.18$ & 0.193 \\
\hline \multicolumn{14}{|l|}{ Osteoporosis } \\
\hline No & 3030 & 23 & 20 & 32 & 18 & 6 & 1.00 & & & & 1.00 & & \\
\hline Yes & 463 & 34 & 22 & 29 & 12 & 3 & 0.70 & $0.58-0.84$ & $<0.001$ & & 0.71 & $0.59-0.86$ & $<0.001$ \\
\hline \multicolumn{14}{|l|}{ Daily calorie intake } \\
\hline$\leq 1750$ & 1007 & 28 & 22 & 30 & 15 & 5 & 1.00 & & & & 1.00 & & \\
\hline $1751-2000$ & 714 & 26 & 21 & 33 & 16 & 4 & 1.02 & $0.86-1.22$ & 0.791 & & 1.02 & $0.86-1.22$ & 0.806 \\
\hline $2000-2400$ & 1037 & 24 & 21 & 33 & 17 & 6 & 1.07 & $0.91-1.26$ & 0.424 & & 1.08 & $0.92-1.28$ & 0.339 \\
\hline$>2400$ & 791 & 20 & 19 & 33 & 23 & 6 & 1.31 & $1.10-1.56$ & 0.003 & 0.005 & 1.33 & $1.11-1.59$ & 0.002 \\
\hline \multicolumn{14}{|l|}{ Daily folate intake } \\
\hline $200-399 \mu \mathrm{g}$ & 2415 & 25 & 21 & 32 & 18 & 5 & 1.00 & & & & 1.00 & & \\
\hline$<200 \mu g$ & 173 & 24 & 24 & 35 & 13 & 3 & 1.01 & $0.77-1.33$ & 0.943 & & 1.00 & $0.76-1.32$ & 1.000 \\
\hline$\geq 400 \mu \mathrm{g}$ & 961 & 24 & 20 & 31 & 18 & 7 & 1.08 & $0.94-1.24$ & 0.297 & 0.364 & 1.10 & $0.96-1.27$ & 0.169 \\
\hline \multicolumn{14}{|l|}{ Physical activity } \\
\hline Moderate & 1620 & 23 & 19 & 33 & 20 & 5 & 1.00 & & & & 1.00 & & \\
\hline Little & 224 & 23 & 19 & 31 & 20 & 7 & 1.07 & $0.82-1.38$ & 0.625 & & 1.00 & $0.77-1.30$ & 0.978 \\
\hline Very active & 1691 & 26 & 22 & 31 & 15 & 5 & 0.83 & $0.73-0.95$ & 0.005 & & 0.86 & $0.75-0.98$ & 0.026 \\
\hline \multicolumn{14}{|l|}{ ALCOHOL } \\
\hline \multicolumn{14}{|l|}{ Current drinker } \\
\hline No & 1477 & 29 & 20 & 32 & 15 & 5 & 1.00 & & & & 1.00 & & \\
\hline Yes & 2072 & 22 & 21 & 32 & 19 & 6 & 1.15 & $1.02-1.31$ & 0.025 & & 1.13 & $0.99-1.28$ & 0.060 \\
\hline \multicolumn{14}{|l|}{ Daily g alcohol } \\
\hline 0 (non-drinker) & 1477 & 29 & 20 & 32 & 15 & 5 & 1.00 & & & & 1.00 & & \\
\hline 0 - less than $10 \mathrm{~g}$ & 1460 & 22 & 21 & 32 & 19 & 6 & 1.13 & $0.99-1.30$ & 0.069 & & 1.11 & $0.97-1.27$ & 0.147 \\
\hline $10 \mathrm{~g}$ or more & 612 & 20 & 21 & 33 & 21 & 6 & 1.20 & $1.01-1.43$ & 0.040 & 0.023 & 1.18 & $0.99-1.41$ & 0.062 \\
\hline \multicolumn{14}{|l|}{ Lifetime alcohol use } \\
\hline Never & 1312 & 29 & 19 & 31 & 15 & 5 & 1.00 & & & & 1.00 & & \\
\hline Ex-drinker & 165 & 23 & 23 & 35 & 16 & 3 & 1.01 & $0.75-1.35$ & 0.955 & & 0.98 & $0.73-1.32$ & 0.912 \\
\hline Current & 2072 & 22 & 21 & 32 & 19 & 6 & 1.15 & $1.01-1.31$ & 0.029 & & 1.13 & $0.99-1.28$ & 0.075 \\
\hline
\end{tabular}




\begin{tabular}{|c|c|c|c|c|c|c|c|c|c|c|c|c|c|}
\hline \multicolumn{14}{|c|}{ Age of alcohol initiation ${ }^{a}$} \\
\hline$\leq 18$ years old & 603 & 17 & 22 & 33 & 21 & 7 & 1.00 & & & & 1.00 & & \\
\hline $19-24$ & 540 & 24 & 19 & 31 & 22 & 5 & 0.99 & $0.80-1.22$ & 0.907 & & 1.10 & $0.89-1.37$ & 0.374 \\
\hline $25-40$ & 508 & 20 & 21 & 35 & 18 & 6 & 0.99 & $0.80-1.23$ & 0.920 & & 1.14 & $0.92-1.42$ & 0.232 \\
\hline$>40$ years old & 146 & 21 & 20 & 32 & 23 & 5 & 1.05 & $0.75-1.45$ & 0.792 & 0.915 & 1.28 & $0.92-1.79$ & 0.149 \\
\hline Before/at 18 years & 1194 & 22 & 20 & 33 & 20 & 5 & 1.00 & & & & 1.00 & & \\
\hline After 18 years old & 603 & 17 & 22 & 33 & 21 & 7 & 1.00 & $0.84-1.20$ & 0.958 & & 0.88 & $0.73-1.05$ & 0.159 \\
\hline After menarche & 1734 & 20 & 21 & 33 & 21 & 6 & 1.00 & & & & 1.00 & & \\
\hline Before/at menarche & 68 & 26 & 22 & 28 & 18 & 6 & 0.66 & $0.42-1.02$ & 0.063 & & 0.66 & $0.42-1.03$ & 0.067 \\
\hline Before/at first pregn. & 1060 & 22 & 21 & 31 & 21 & 5 & 1.00 & & & & 1.00 & & \\
\hline After first pregnancy & 463 & 22 & 22 & 35 & 16 & 5 & 1.00 & $0.82-1.23$ & 0.973 & & 1.11 & $0.90-1.36$ & 0.324 \\
\hline \multicolumn{14}{|l|}{ SMOKING } \\
\hline \multicolumn{14}{|l|}{ Current smoker } \\
\hline No & 2691 & 26 & 20 & 32 & 16 & 5 & 1.00 & & & & 1.00 & & \\
\hline Yes & 858 & 19 & 21 & 32 & 21 & 6 & 0.95 & $0.82-1.09$ & 0.476 & & 0.91 & $0.79-1.05$ & 0.210 \\
\hline \multicolumn{14}{|l|}{ Daily cigarettes } \\
\hline $0-5$ & 251 & 17 & 21 & 33 & 23 & 6 & 1.00 & & & & 1.00 & & \\
\hline $6-15$ & 315 & 20 & 19 & 30 & 23 & 8 & 0.68 & $0.52-0.88$ & 0.004 & & 0.83 & $0.61-1.13$ & 0.239 \\
\hline$>15$ & 292 & 20 & 24 & 35 & 17 & 4 & 0.78 & $0.48-1.26$ & 0.317 & 0.007 & 0.68 & $0.50-0.93$ & 0.017 \\
\hline \multicolumn{14}{|l|}{ Lifetime tobacco } \\
\hline Never & 2054 & 28 & 21 & 32 & 15 & 4 & 1.00 & & & & 1.00 & & \\
\hline Ex-smoker & 637 & 22 & 19 & 31 & 21 & 8 & 1.18 & $1.00-1.40$ & 0.053 & & 1.08 & $0.91-1.28$ & 0.373 \\
\hline Current & 858 & 19 & 21 & 32 & 21 & 6 & 0.99 & $0.85-1.15$ & 0.901 & & 0.93 & $0.80-1.08$ & 0.353 \\
\hline \multicolumn{14}{|l|}{ Accumulated } \\
\hline$\leq 300$ & 606 & 17 & 19 & 33 & 24 & 7 & 1.00 & & & & 1.00 & & \\
\hline $301-500$ & 308 & 24 & 19 & 27 & 21 & 9 & 0.78 & $0.60-1.00$ & 0.049 & & 0.76 & $0.59-0.99$ & 0.038 \\
\hline $501-700$ & 246 & 19 & 17 & 37 & 19 & 7 & 0.90 & $0.68-1.18$ & 0.436 & & 0.88 & $0.67-1.16$ & 0.370 \\
\hline$>700$ & 230 & 24 & 27 & 29 & 17 & 2 & 0.72 & $0.54-0.95$ & 0.021 & 0.031 & 0.70 & $0.53-0.93$ & 0.014 \\
\hline \multicolumn{14}{|c|}{ Age tobacco initiation ${ }^{a}$} \\
\hline$\leq 18$ years old & 871 & 16 & 21 & 32 & 24 & 8 & 1.00 & & & & 1.00 & & \\
\hline $19-24$ & 317 & 25 & 19 & 32 & 19 & 5 & 0.84 & $0.65-1.07$ & 0.154 & & 0.82 & $0.65-1.06$ & 0.128 \\
\hline $25-40$ & 174 & 31 & 18 & 29 & 18 & 4 & 0.94 & $0.68-1.30$ & 0.701 & & 0.96 & $0.70-1.33$ & 0.819 \\
\hline$>40$ years old & 34 & 26 & 18 & 38 & 15 & 3 & 1.00 & $0.52-1.89$ & 0.983 & 0.486 & 1.14 & $0.60-2.19$ & 0.679 \\
\hline Before/at 18 years & 871 & 16 & 21 & 32 & 24 & 8 & 1.00 & & & & 1.00 & & \\
\hline After 18 years old & 525 & 27 & 19 & 31 & 18 & 5 & 0.84 & $0.71-1.08$ & 0.220 & & 0.88 & $0.71-1.09$ & 0.249 \\
\hline After menarche & 1332 & 20 & 20 & 32 & 21 & 7 & 1.00 & & & & 1.00 & & \\
\hline Before/at menarche & 72 & 11 & 21 & 33 & 25 & 10 & 1.11 & $0.72-1.70$ & 0.632 & & 1.15 & $0.75-1.76$ & 0.524 \\
\hline Before/at first pregn. & 1374 & 19 & 18 & 32 & 23 & 8 & 1.00 & & & & 1.00 & & \\
\hline After first pregnancy & 174 & 30 & 23 & 29 & 14 & 4 & 0.84 & $0.62-1.13$ & 0.245 & & 1.06 & $0.78-1.46$ & 0.683 \\
\hline
\end{tabular}

'Simple model adjusted for age at mammography, BMI, menopausal status, and screening program. ${ }^{2}$ Extended model adjusted for age at mammo BMI, menopausal status, and screening program, plus number of live births, HRT use, current smoker, and current alcohol drinker status. ${ }^{*}$ To calcul trends, variables were modeled as continuous variables; ${ }^{\mathrm{a}}$ Variables linked to age of alcohol and smoking initiation were analyzed only in drinkers a smokers/ex-smokers. 
TABLE 2. Associated ORs and 95\% Cls for a higher Boyd category.

\begin{tabular}{|c|c|c|c|c|c|c|c|c|c|c|}
\hline \multirow[b]{2}{*}{ VARIABLES } & \multicolumn{5}{|c|}{ PRE \& PERIMENOPAUSAL ${ }^{1}$} & \multicolumn{5}{|c|}{ POSTMENENOPAUSAL $^{2}$} \\
\hline & $\mathrm{N}$ & OR & $95 \% \mathrm{Cl}$ & $p$ & $\begin{array}{l}p \text { for } \\
\text { trend }\end{array}$ & $\mathrm{N}$ & OR & $95 \% \mathrm{Cl}$ & $p$ & $\begin{array}{l}p \text { for } \\
\text { trend }\end{array}$ \\
\hline \multicolumn{11}{|l|}{ ALCOHOL DRINKING } \\
\hline \multicolumn{11}{|l|}{ Current drinker } \\
\hline No & 301 & 1.00 & & & & 1174 & 1.00 & & & \\
\hline Yes & 499 & 1.04 & $0.79-1.36$ & 0.801 & & 1573 & 1.15 & $1.00-1.32$ & $\begin{array}{l}0.058 \\
0.058\end{array}$ & \\
\hline \multicolumn{11}{|l|}{ Daily g alcohol } \\
\hline 0 (non-drinker) & 301 & 1.00 & & & & 1174 & 1.00 & & & \\
\hline 0 - less than 10 & 373 & 1.07 & $0.80-1.42$ & 0.656 & & 1087 & 1.10 & $0.94-1.29$ & 0.223 & \\
\hline 10 or more & 126 & 0.95 & $0.65-1.40$ & 0.790 & 0.925 & 486 & 1.26 & $1.03-1.53$ & 0.023 & 0.022 \\
\hline \multicolumn{11}{|l|}{ Lifetime alcohol use } \\
\hline Never & 263 & 1.00 & & & & 1047 & 1.00 & & & \\
\hline Ex-drinker & 38 & 0.65 & $0.35-1.23$ & 0.185 & & 127 & 1.13 & $0.81-1.58$ & 0.470 & \\
\hline Current & 499 & 0.98 & $0.74-1.30$ & 0.887 & & 1573 & 1.16 & $1.00-1.35$ & 0.043 & \\
\hline \multicolumn{11}{|c|}{ Age of alcohol initiation ${ }^{a}$} \\
\hline$\leq 18$ years old & 225 & 1.00 & & & & 378 & 1.00 & & & \\
\hline $19-24$ & 123 & 1.03 & $0.69-1.55$ & 0.870 & & 417 & 1.10 & $0.85-1.42$ & 0.477 & \\
\hline $25-40$ & 101 & 1.03 & $0.67-1.57$ & 0.893 & & 407 & 1.13 & $0.87-1.46$ & 0.366 & \\
\hline$>40$ years old & 21 & 2.57 & $1.06-6.26$ & 0.038 & 0.258 & 125 & 1.12 & $0.78-1.62$ & 0.534 & 0.381 \\
\hline Before/at 18 years old & 245 & 1.00 & & & & 949 & 1.00 & & & \\
\hline After 18 years old & 225 & 0.91 & $0.65-1.26$ & 0.564 & & 378 & 0.90 & $0.72-1.12$ & 0.336 & \\
\hline After menarche & 451 & 1.00 & & & & 1283 & 1.00 & & & \\
\hline Before/at menarche & 20 & 0.49 & $0.21-1.14$ & 0.098 & & 48 & 0.70 & $0.41-1.19$ & 0.189 & \\
\hline Before/at first pregn & 300 & 1.00 & & & & 760 & 1.00 & & & \\
\hline After first pregnancy & 100 & 1.04 & $0.68-1.59$ & 0.853 & & 363 & 1.12 & $0.89-1.41$ & 0.342 & \\
\hline \multicolumn{11}{|l|}{ SMOKING } \\
\hline \multicolumn{11}{|l|}{ Current smoker } \\
\hline No & 549 & 1.00 & & & & 2141 & 1.00 & & & \\
\hline Yes & 251 & 0.86 & $0.65-1.13$ & 0.278 & & 606 & 0.93 & $0.79-1.10$ & $\begin{array}{l}0.415 \\
0.415\end{array}$ & \\
\hline \multicolumn{11}{|l|}{ Daily cigarettes } \\
\hline $0-5$ & 73 & 1.00 & & & & 178 & 1.00 & & & \\
\hline $6-15$ & 92 & 1.01 & $0.57-1.79$ & 0.970 & & 223 & 0.81 & $0.56-1.19$ & 0.285 & \\
\hline$>15$ & 86 & 0.80 & $0.45-1.42$ & 0.442 & 0.434 & 205 & 0.68 & $0.46-0.99$ & 0.046 & 0.046 \\
\hline \multicolumn{11}{|l|}{ Lifetime tobacco } \\
\hline Never & 342 & 1.00 & & & & 1712 & 1.00 & & & \\
\hline Ex-smoker & 207 & 1.06 & $0.77-1.47$ & 0.721 & & 429 & 1.10 & $0.90-1.34$ & 0.366 & \\
\hline Current & 251 & 0.88 & $0.65-1.19$ & 0.398 & & 606 & 0.95 & $0.80-1.13$ & 0.579 & \\
\hline \multicolumn{11}{|c|}{ Accumulated cigarettes life } \\
\hline$\leq 300$ & 215 & 1.00 & & & & 391 & 1.00 & & & \\
\hline $301-500$ & 106 & 0.88 & $0.57-1.35$ & 0.555 & & 202 & 0.73 & $0.53-1.01$ & 0.054 & \\
\hline $501-700$ & 87 & 0.82 & $0.52-1.30$ & 0.400 & & 157 & 0.92 & $0.65-1.29$ & 0.628 & \\
\hline$>700$ & 37 & 0.72 & $0.37-1.40$ & 0.337 & 0.238 & 193 & 0.70 & $0.51-0.96$ & 0.028 & 0.053 \\
\hline \multicolumn{11}{|c|}{ Age of smoking initiation ${ }^{a}$} \\
\hline$\leq 18$ years old & 350 & 1.00 & & & & 519 & 1.00 & & & \\
\hline $19-24$ & 70 & 0.66 & $0.40-1.08$ & 0.098 & & 247 & 0.92 & $0.69-1.22$ & 0.557 & \\
\hline $25-40$ (or $\geq 25$ in prem.) & 26 & 0.81 & $0.37-1.66$ & 0.590 & 0.177 & 153 & 0.96 & $0.67-1.37$ & 0.824 & \\
\hline$>40$ years old & & & & & & 29 & 1.36 & $0.67-2.80$ & 0.396 & 0.920 \\
\hline Before/at 18 years old & 350 & 1.00 & & & & 519 & 1.00 & & & \\
\hline After 18 years old & 76 & 0.71 & $0.46-1.09$ & 0.119 & & 429 & 0.95 & $0.74-1.22$ & 0.700 & \\
\hline After menarche & 411 & 1.00 & & & & 919 & 1.00 & & & \\
\hline Before/at menarche & 36 & 1.36 & $0.73-2.53$ & 0.333 & & 36 & 1.00 & $0.55-1.83$ & 0.992 & \\
\hline
\end{tabular}




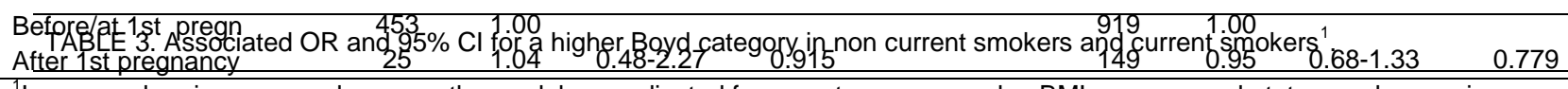

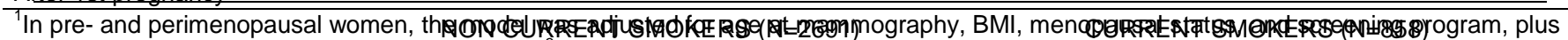
number of live births, and current smoker status. In postmenopausal women, the model was adjusted for the same variables as well as $H R T$

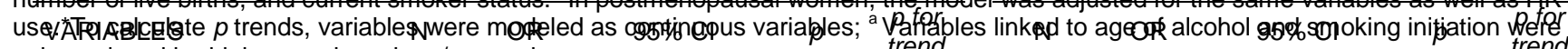
only analyzed in drinkers and smokers/ex-smokers.

Current drinker

No

Yes

$1169 \quad 1.00$

$1522 \quad 1.15$

$0.99-1.32$

0.063

$308 \quad 1.00$

$550 \quad 1.06$

0.82- 1.37

0.672

Daily $g$ alcohol

0 (non-drinker)

0 - less than 10

10 or more

116

$079 \quad 1.11$

0.95- 1.29

0.207

1.02- 1.53

$0.034 \quad 0.029$

308

381

$169 \quad 1.00$

0.82- $1.44 \quad 0.562$

$0.70-1.41 \quad 0.984$

0.916

Lifetime alcohol use

Never

$1058 \quad 1.00$

Ex-drinker

$111 \quad 0.92$

Current

$1522 \quad 1.14$

0.64- 1.32

0.650

0.98- $1.32 \quad 0.089$

$426 \quad 1.00$

Age of alcohol initiation

$\leq 18$ years old

$254 \quad 1.00$

$54 \quad 1.15$

$550 \quad 1.09$

0.67- $1.97 \quad 0.601$

0.82- $1.43 \quad 0.562$ 


\begin{tabular}{|c|c|c|c|c|c|c|c|c|c|c|}
\hline $19-24$ & 375 & 1.13 & $0.87-1.46$ & 0.354 & & 165 & 1.04 & $0.70-1.55$ & 0.843 & \\
\hline $25-40$ & 366 & 1.13 & $0.87-1.47$ & 0.357 & & 142 & 1.14 & $0.75-1.73$ & 0.533 & \\
\hline$>40$ years old & 114 & 1.33 & $0.91-1.95$ & 0.136 & 0.146 & 32 & 1.06 & $0.51-2.19$ & 0.873 & 0.595 \\
\hline Before/at 18 years old & 855 & 1.00 & & & & 339 & 1.00 & & & \\
\hline After 18 years old & 426 & 0.87 & $0.70-1.08$ & 0.192 & & 177 & 0.92 & $0.66-1.30$ & 0.647 & \\
\hline After menarche & 1234 & 1.00 & & & & 500 & 1.00 & & & \\
\hline Before menarche & 52 & 0.50 & $0.29-0.85$ & 0.010 & & 16 & 1.52 & $0.63-3.65$ & 0.347 & \\
\hline Before first pregnancy & 752 & 1.00 & & & & 308 & 1.00 & & & \\
\hline After first pregnancy & 343 & 1.12 & $0.88-1.42$ & 0.361 & & 120 & 1.09 & $0.73-1.62$ & 0.669 & \\
\hline
\end{tabular}




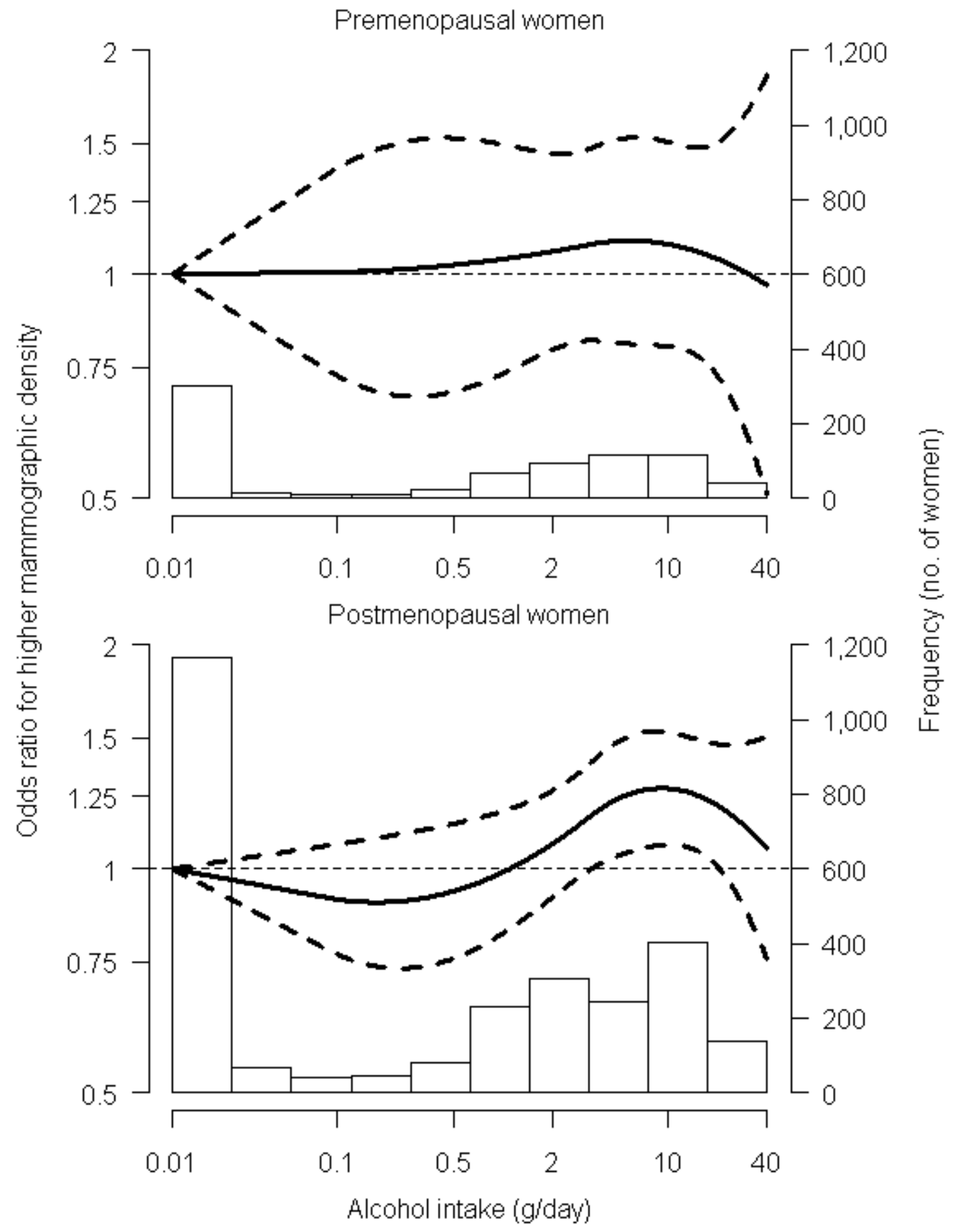

